\title{
Citizen Science as a Pedagogical Tool in Chemistry Education: Students' Attitudes and Teachers' Perceptions
}

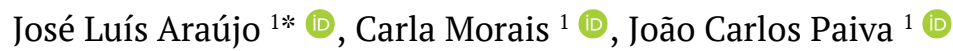

${ }^{1}$ CIQUP, Institute of Molecular Sciences (IMS), Science Education Unit, Department of Chemistry and Biochemistry, Faculty of Sciences, University of Porto, Porto, PORTUGAL

*Corresponding Author: jose.araujo@fc.up.pt

Citation: Araújo, J. L., Morais, C., \& Paiva, J. C. (2022). Citizen Science as a Pedagogical Tool in Chemistry Education: Students' Attitudes and Teachers' Perceptions. Interdisciplinary Journal of Environmental and Science Education, 18(2), e2271. https://doi.org/10.21601/ijese/11841

ARTICLE INFO

Received: 3 Jan. 2022

Accepted: 1 Mar. 2022

\begin{abstract}
The need of promoting the affective dimension of chemistry literacy in students, through expressions of interest in chemistry-related topics and positive attitudes toward this field, has been emphasized in chemistry education. Thus, the purpose of this study was to understand students' attitudes toward chemistry between the ages of 12 and 14, as well as how their participation in a citizen science project called Perceiving the Value of Chemistry behind water and microplastics (PVC) contributed to possible attitude changes. Although the research focus was chemistry education, chemistry and physics are taught as part of one subject in Portugal, so the attitudes towards physics and chemistry scale was used as a pre- and post-test. The pre-test showed positive attitudes towards physics and chemistry. In the post-test, the control group exhibited significantly negative changes in attitude, in all dimensions; whereas the experimental group revealed no significant changes. Pedagogical dynamics also affect students' attitudes toward chemistry, so we undertook interviews to investigate the project's impact on the pedagogical practices of the nine participating teachers. The results suggest that activities developed within the PVC project were formative for the teachers, allowing them to reflect on their practices and promoting an interdisciplinary approach to the topics addressed, in addition to enabling students to use knowledge in different and new perspectives. Moreover, through the development of pedagogical resources and training within this project, teachers recognized that they would continue this experience.
\end{abstract}

Keywords: attitudes towards physics and chemistry, chemical literacy, teaching practices, citizen science educational projects

\section{CHEMICAL LITERACY AND ATTITUDES}

According to Cavas et al. (2013), "scientific literacy is the collective abilities and skills to function as a responsible citizen in scientifically and technologically dominated society" (p. 384). For Cavas et al. (2013), scientific literacy definition includes not only the understanding and knowledge about science but also attitudes and values to science and technology and their impact on society. The attitude concept assumes a central role in social psychology and, particularly, in educational sciences (Dalgety et al., 2003). Although the concept of attitude has a wide range of definitions that emerged from the research carried out in this field over the last decades, all of these definitions agree that attitude is a complex concept that represents "the tendency to think, feel, or act positively or negatively toward objects in our environment" (Salta \& Tzougraki, 2004, p. 535). More particularly, as stated by Lu et al. (2016), this concept may be understood as a characteristic of human beings expressing "the feelings, beliefs, and values held about an object, which in terms of science may include enthusiasm about science, perceptions of school science, and contributions of science to society or of scientists themselves" (p. 2177).

Beyond scientific literacy in its broadest sense, it is also important to foster more specific literacies, such as chemistry literacy (Chang \& Chiu, 2005; Gilbert \& Treagust, 2009; Talanquer \& Sevian, 2013). Kohen et al. (2020) argue for the need to promote students' chemical literacy because developing an "ability to understand, and critically evaluate ideas and arguments in the media pertaining to chemistry content, enables one to cope with situations that citizens are likely to encounter in real-life scientific and technological contexts which surround them" (p. 250). As highlighted by Chang and Goldsby (2016), "chemistry is an active, evolving science that has vital importance to our world, in both the realm of nature and the realm of society" (p. 2). Thus, promoting chemical literacy among students becomes essential because, as mentioned by Kohen et al. (2020), "by fostering chemical literacy, students understand better the role of chemistry in their lives and society and acquire the 
skills to actively participate in the relevant civic and political debates" (p. 251). Chemical literacy, in addition to encompassing the contexts, knowledge and skills related to chemistry, also has an affective dimension that pertains to the expression of interest in matters associated with chemistry (Kohen et al., 2020; Shwartz et al., 2006). For example, Kohen et al. (2020) and Osborne et al. (2003) have found that students reveal distinct levels of interest for different scientific areas. In the case of chemistry, students often reveal little interest, since identifying its relevance in daily life is less obvious (Salta \& Tzougraki, 2004; Tytler \& Osborne, 2012). On the other hand, Cheung (2009) stated that "students who had a less positive attitude to chemistry almost invariably obtained lower examination marks" (p. 76). For this reason, promoting positive attitudes towards chemistry has become one of the aims of the subject's curricula (Hofstein \& Mamlok-Naaman, 2011), aiming to enhance chemistry learning and allow students to be "able to adapt with the changes in their daily life and at the same time contribute to the development of science and technology of the country in a sustainable manner" (Heng \& Karpudewan, 2015, p. 889). Nonetheless, although the importance of attitudes (and of other affective variables) in the learning process has long been recognized by research in science education (Vilia \& Candeias, 2020), the cognitive dimension of learning still takes on a central (and often exclusive) role in the implementation of curricula, in the teaching practices of teachers, and in evaluating students' success or failure (Hansson et al., 2021; Vilia \& Candeias, 2020). In this regard, Osborne and Collins (2000) found that chemistry is the subject that high school students, in the United Kingdom, least prefer and towards which they have the most negative attitudes. Furthermore, Ibrahim and Iksan (2018) mention that students consider chemistry to be "one of the most difficult subjects and students tend to have a negative attitude towards chemistry" (p. 53). Moreover, Dalgety et al. (2003) and Hofstein et al. (1977), as well as Salta and Tzougraki (2004), analysed the attitudes towards chemistry of students in primary and secondary education and found their attitudes tended to decrease over the course of their academic trajectory. Regarding the Portuguese reality, studies on the attitudes of Portuguese students towards chemistry are still scarce and report conflicting results. For example, Fernandes (2007) conducted a study on Portuguese students' attitudes towards physics and chemistry, which indicated that students consider the subject interesting, accessible and easily related to daily aspects. Moreover, Fernandes (2007) reports that girls exhibit more favourable attitudes and performances than boys regarding the subject of physics and chemistry. In addition, because the scientific areas of chemistry and physics are taught together as one subject from $7^{\text {th }}$ to $11^{\text {th }}$ grade, the national panorama of students' attitudes toward these subjects is often sketched jointly (Neto et al., 2013; Vilia \& Candeias, 2020; Vilia et al., 2017). Vilia and Candeias (2020), on the other hand, analysed the impact of students' attitudes towards physics and chemistry on their academic performance. This more recent study indicates that boys have more positive attitudes than girls regarding pleasure in learning physics and chemistry and self-confidence towards this subject. Vilia and Candeias (2020) also report that students' positive attitudes towards the dimensions of competence, anxiety, and pleasure in learning, present in the attitude scale used in the study, proved to be factors with great impact on students' performance in the subject of physics and chemistry. Vilia and Candeias (2020) emphasize the importance of taking into account this affective dimension in pedagogical dynamics, particularly in the subject of physics and chemistry, by involving students in more student-friendly methodologies, such as hands-on dynamics or inquiry-based learning, and by exploring contexts that are familiar to students and relevant to their daily lives. According to Vilia and Candeias (2020), these dynamics promote interest and pleasure in learning physics and chemistry, in addition to reducing the anxiety that students feel towards the subject, thus promoting academic success.

Altundag and Alkan (2018) mention that promoting students' attitudes towards sciences, such as physics and chemistry, is enhanced by changing learning environments, in particular, by exploring significant and relevant contexts that "make the learning process of the content and scientific concepts easy” (p. 39). Altundag and Alkan (2018, p. 39) conclude that teaching dynamics based on relevant and current contexts generate positive changes in attitudes towards chemistry, in particular, "towards the idea that the daily life chemistry ensures concrete thinking, a more effective interpretation of information, understanding the essence of chemistry, facilitating comprehending topics, and making information more useful and permanent." As such, the teacher is responsible for innovating and offering students relevant, diversified pedagogical dynamics, in order to actively involve them in the construction of their learning. In light of the above, the present PVC project (presented in greater detail by Araújo et al. (2021) and summarized below) aimed to promote the development of chemical literacy among students, in the affective and cognitive domains. Additionally, it intended to integrate, within the classroom, a citizen science approach that allows students to be an active part of the scientific research process and empowers teachers to adopt new pedagogical approaches. As mentioned by Harlin et al. (2018) and Scheuch et al. (2018), citizen science projects have great pedagogical potential, particularly in terms of promoting positive attitudes in students.

\section{PROMOTING CITIZEN SCIENCE IN CHEMISTRY TEACHING THROUGH PVC PROJECT}

Citizen science is characterized by citizens' engagement in scientific research that is responsive to societal needs (Strasser et al., 2019). This approach encompasses several levels of public involvement in science: "from being better informed about science, to participating in the scientific process itself by observing, gathering or processing data" (European Commission, 2021). This is an approach "applicable across all scientific disciplines, alongside a variety of disciplinary traditions and research methods" (European Citizen Science Association, 2020, p. 3).

Bonn et al. (2018) refer to the importance of this approach for science education, because it increases scientific literacy and science capital. In addition, Harlin et al. (2018) and Tulloch et al. (2013) highlight the increase of studies involving 
students in citizen science approach. This approach builds a bridge between science-related contents and relevant social and environmental contexts, on which these projects are mainly focused. This relationship is evident in scientific areas such as astronomy, biology, ecology, or the environment, which focus on some of the most relevant and far-reaching citizen science projects (Follett \& Strezov, 2015; Hecker et al., 2018). According to Motion (2019), the preponderance of citizen science projects in these areas is due to the "rich history of 'citizen naturalists' and a long tradition of using data from 'amateurs' who have participated in projects recording the population of different species, migratory patterns and behaviours." Nonetheless, despite the potential of citizen science, there is little expression of citizen science in chemistry and the formal assessment of citizen science contributions to students' education are still not well described in the literature (Follett \& Strezov, 2015; Hecker et al., 2018). However, despite the little expression of citizen science in chemistry, Bellocchi et al. (2016) emphasize that citizen science approaches are a path that allows for a significant improvement in chemistry teaching and learning processes.

Indeed, these approaches can help overcome chemistry's intrinsic cognitive difficulties (interrelation of its macroscopic, submicroscopic, and symbolic dimensions) and the fact that students perceive chemistry as difficult, uninteresting, and disconnected from reality (Aikenhead, 2003). Cardellini (2012) also states that lack of interest in chemistry may be related to the fact that expository teaching methods are still the most predominant among teaching practices. Through the exploration of relevant socio-scientific contexts, citizen science can be an excellent way to promote the creation of an appropriate scientific knowledge basis, stimulating chemistry interest mirrored in the surrounding environment and empowering teachers by diversifying their practices (Kelemen-Finan et al., 2018).

The pedagogical potential of citizen science educational projects, thus, depends on the teaching strategies and resources used by teachers and their suitability for students. Since preparing materials and planning strategies are demanding tasks, they often become obstacles to the implementation of these projects by teachers; thus, "citizen science programmes need to offer relevant teaching material to ease the work of teachers in connecting them to school curriculum" (Harlin et al., 2018, p. 413). Therefore, we developed an educational citizen science project called Perceiving the Value of Chemistry behind water and microplastics (PVC) that aims to reveal chemistry's social role and its contribution to the remediation of environmental issues related to marine litter and coastal waters quality. The project was implemented in three stages that included online and practical-laboratory activities, field trips and science communication tasks:

1. online tasks on a Moodle platform ("such as guided searches, video visualization, interpretation, and creation of posters and infographics" (Araújo et al., 2020 , p. 102)) to raise awareness to marine litter problems such as the presence of plastics and microplastics in coastal waters and its consequences to the environment; at the same time, the project intended to reveal the importance of chemistry's preventive role in combating these environmental issues;

2. the sampling of coastal waters and polluting plastics from beaches, and analysing the collected waters' physicochemical parameters $(\mathrm{pH}$, temperature, turbidity, percentage of dissolved oxygen, salinity, and concentration of nitrates and nitrites), as well as the qualitative identification of (micro)plastics, using pedagogical kits (Araújo et al., 2020) specifically developed for the purpose, to promote the learning of chemistry curriculum contents related to the project (Araújo et al., 2021); and

3. sharing the results of the coastal water monitoring with the Earth Echo Water Challenge, a citizen science project platform, and organizing exhibitions in schools to disseminate the work students developed in the PVC project, as well as lectures with invited scientists to mobilize students' acquired knowledge and to develop their communication skills.

As such, part of the evaluation of the PVC project's impact involved understanding students' attitudes towards the subject of physics and chemistry and how their engagement in PVC project promoted any changes in their attitudes. It must be mentioned that, in Portugal, the scientific areas of physics and chemistry are taught together, from $7^{\text {th }}$ to $11^{\text {th }}$ grade, with each component being clearly identified and occupying about half of the academic year. Thus, for this study, our focus was on the chemistry component of the physics and chemistry subject. We also aimed to understand the meanings teachers attribute to this experience and how their involvement in the PVC project contributed to their teaching practices.

\section{METHODS}

\section{Participants}

The PVC project took place during the 2018/2019 school year. In this research were involved 26 chemistry classes making a total of 574 students. These students belong to three school levels of the middle school-Key Stage 3 (KS3) aged 1214 in Portuguese schools $-7^{\text {th }}, 8^{\text {th }}$, and $9^{\text {th }}$ grades. The 26 chemistry classes were taught by nine teachers (ages 30 to 58, with an average of more than 20 years of teaching experience) from one private and three public schools in Portugal's northern coast region. The nine teachers volunteered to participate in the study by monitoring their students' participation in the PVC project and assisting with data collection instrument application. Six classes were chosen at random from the four schools involved in the PVC project (two classes for each grade, 132 students: 65 boys and 67 girls) to be included in the control group (CG). The other 20 classes (442 students: 208 boys and 234 girls) were included in the experimental group (EG). Both groups, according to students' school year, receive the same physics and chemistry curriculum instruction. In each 90-minute lesson, students worked on the project in small groups comprising two to five elements, over a period of seven months. Araújo et al. (2021) presented in detail the PVC project implemented activities 
among both EG and CG. The implementation of the various stages of the PVC project was actively conducted by the teachers involved, who collaborated in this research by monitoring the participation of their students in the various activities of the PVC project, in addition to assisting in the application of the data collection instruments, always in close collaboration with researchers, with the latter playing a mediator role in the dynamics designed.

To assess the PVC project's impact on teaching practices, interviews were conducted with the participating teachers. Two specialists in science education attested to the content validity of the developed interview guide. Subsequently, the audio of the interviews was transcribed and analysed using the content analysis technique. All participation in this study was voluntary. The teachers and parents of the students signed an informed consent form to authorize participation in the study. This consent form described the activities in which students would be involved and ensured the anonymous and confidential treatment of all personal data.

\section{Procedures}

\section{Attitude toward physics and chemistry scale}

As a tool to understand students' attitudes towards the subject of physics and chemistry, we used the attitude toward physics and chemistry questionnaire (ATPCQ), developed by Neto et al. (2011). This instrument proved to be appropriate for the proposed research objectives, namely understanding students' perceptions, in the affective domain, regarding this subject (the ATPCQ was validated and implemented in a sample with similar characteristics to the sample used in this study, that is, Portuguese KS3 students).

The ATPCQ comprises 26 closed-response items for students to express their level of agreement, according to a 7 point Likert-type scale: where the maximum score ( 7 points) pertains to the highest level of agreement and the minimum score (1 point) represents the highest level of disagreement. The average response time was 25 minutes. For the purposes of content validation, the ATPCQ was first answered by a student from each KS3 grade, in order to ensure that all statements presented were intelligible and easy to understand. The questionnaire was also analysed by two experts in chemistry education. This validation process led to the conclusion that, in order to make the items more easily understandable, it would be important to transform items written in negative form into affirmative items. As reported by Neto et al. (2011, 2013), previous applications of the ATPCQ led to different results regarding the dimensions of this scale. Specifically, in a first psychometric analysis of the scale, the authors suggested the existence of three components: pleasure, ease and enjoyment in studying physics and chemistry and the utility of physics and chemistry in daily life (Neto et al., 2011); however, in a subsequent study, the component structure of the scale was different, suggesting the existence of the following components: pleasure in learning, anxiety, competence and utility (Neto et al., 2013). Given these facts, we also decided to conduct an exploratory statistical analysis of the modified ATPCQ, which we call attitude towards physics and chemistry scale (ATPCS).
In addition, students also answered a set of questions that aimed to collect sociodemographic information, such as gender, grade and the school they were attending. The attitude scale was anonymized and coded so that students' responses could be compared between the different moments this instrument was applied.

\section{Data collection}

The students of the EG and CG answered a printed version of the questionnaire, as a pre-test, during the first two months of the 2018/2019 school year, before the PVC project implementation began. At the end of the school year, and after the completion of the PVC project, the participating students returned to answer the same questionnaire, as a post-test. This data collection took place during a physics and chemistry class and the administration of the scales was monitored by the teacher in each class.

Furthermore, data were also collected regarding teachers' perceptions on the use of citizen science approaches as pedagogical tools, through interviews conducted with the teachers. The content validity of the developed interview protocol was attested by two experts in chemistry education. Following we gave re some examples of questions presented in the developed interview protocol: "Regarding the materials and procedures provided by the PVC project, how do you assess their suitability for students? How did these materials relevant for the implementation of the laboratory activities?", "Do you consider that participating in the PVC project was an asset to your teaching practices? How did your participation in this project contribute to improve the quality of your lessons?" or "Do you consider that the participation in the PVC project promoted inter and multidisciplinary learning? Can you give us some examples?”

\section{Data analysis}

The data obtained through the application of the ATPCS was submitted to statistical analysis using the IBM SPSS statistics software (Version 25). To better describe students' responses, descriptive and inferential statistics procedures such as such as principal component analysis (PCA) and reliability analysis were used. The audio of the interviews conducted with the teachers was transcribed and was analysed through content analysis.

\section{RESULTS}

\section{Attitude Towards Physics and Chemistry}

In order to define the dimensions of analysis emerging from the ATPCS, a PCA with varimax rotation was performed. A four-component solution was supported by the analysis of the scree plot (Figure 1), as suggested by Field (2009). Combined these four components explained $68.8 \%$ of the variance (above the minimum desirable limit of 60\%) (Costello \& Osborne, 2005). The Kaiser-Meyer-Olkin measure of sampling adequacy (KMO) indicated that the sample adequacy regular style test of sphericity was statistically significant, $\chi 2$ $(120)=17110.92 ; \mathrm{p}<.001)$, allowing us to verify that the variables analyzed are related to each other, thus the application of principal component analysis is adequate. 


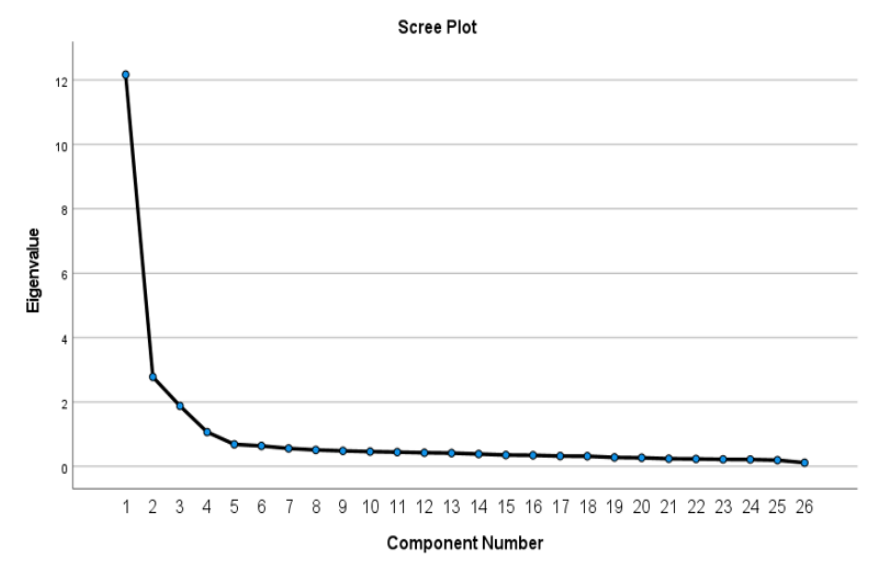

Figure 1. Scree plot of attitude towards physics \& chemistry scale

According to Field (2009), Table 1 shows the items that have saturation values above 0.50 in correlation matrix.

The interpretation of the results led to the definition of dimensions underlying each component that emerged from the analysis, as shown in Table 2. The first component, from which emerged dimension 1 (easiness), comprises a set of eight items (1-8) about students' easiness towards the subject of physics and chemistry and its study and learning. Dimension 2 (negative affectivity) represented in the second component, includes seven items (9-15) about students' feelings towards this subject and its study. Dimension 3 (motivation) focuses on the motivational aspect towards the subject and its study, present in seven of the items (16-22) of this attitude scale.
Finally, the last component comprises dimension 4 (utility and competence), which refers to the application of physics and chemistry in daily life, as well as the contribution of this subject to the development of students' skills, encompassing four items of the scale (23-26).

An analysis of the scale's reliability (Cronbach's alpha) was conducted to assess its internal consistency. This analysis reveals excellent internal consistency values for the components: dimension 1 (easiness) (0.934) and dimension 3 (motivation) (0.908); and reveals good values for the remaining components: dimension 2 (negative affectivity) (0.898) and dimesion 4 (utility and competence) (0.847).

All dimensions reveal a Cronbach's alpha value above 0.80 , thus the reliability of the scale is high. The dimensions of this attitude scale present adequate internal consistency as itemtotal correlations are positive and have limit values above 0.5 (Briggs \& Cheek, 1986). The results of the PCA suggest that, before participating in this project, overall, students exhibited more positive attitudes towards dimension 2 (negative affectivity) ( $\mathrm{M}=5.46 ; \mathrm{SD}=1.18)$, followed by dimension 4 (utility and competence $(\mathrm{M}=4.79 ; \mathrm{SD}=1.26)$ and dimension 1 (easiness) $(\mathrm{M}=4.52 ; \mathrm{SD}=1.24)$. Lastly, there is dimension 3(motivation) ( $\mathrm{M}=4.33$; $\mathrm{SD}=1.32$ ), which also exhibits a mean value above the scales' intermediate point (Table 2).

To better understand how the PVC citizen science project promoted attitudinal changes among students regarding the physics and chemistry subject, the results of the pre-test application of this scale were compared with the results obtained in the post-test, for EG and CG.

Table 1. PCA with varimax rotation of the attitudes towards physics and chemistry scale

\begin{tabular}{|c|c|c|c|c|}
\hline \multirow{2}{*}{ Items } & \multicolumn{4}{|c|}{ Component } \\
\hline & 1 & 2 & 3 & 4 \\
\hline 1. I easily get good grades in physics and chemistry. & .865 & & & \\
\hline 2. I manage to get good results in physics and chemistry without difficulty. & .852 & & & \\
\hline 3. It is easy for me to be a good student in physics and chemistry. & .818 & & & \\
\hline 4. It is easy for me to solve physics and chemistry problems. & .808 & & & \\
\hline 5. I do the physics and chemistry activities with ease. & .801 & & & \\
\hline 6. I easily understand what is explained in physics and chemistry. & .718 & & & \\
\hline 7. "For me, physics and chemistry is a difficult subject. & .662 & & & \\
\hline 8. I understand the practical application of physics and chemistry. & .545 & & & \\
\hline 9. "The subject of physics and chemistry irritates me. & & .826 & & \\
\hline 10. "Solving physics and chemistry problems is discouraging for me. & & .798 & & \\
\hline 11. "It would be good to stop studying physics and chemistry. & & .776 & & \\
\hline 12. "The expression "physics and chemistry" gives me an unpleasant feeling. & & .722 & & \\
\hline 13. "My interest in physics and chemistry decreases throughout my time in school. & & .713 & & \\
\hline 15. "When I stumble upon a physics and chemistry problem I feel like giving up. & & .672 & & \\
\hline 16. On the days I have physics and chemistry classes, I have more interest in going to school. & & & .742 & \\
\hline 17. Studying physics and chemistry gives me joy. & & & .733 & \\
\hline 18. Studying physics and chemistry calms me. & & & .711 & \\
\hline 19. I have fun when I study physics and chemistry. & & & .696 & \\
\hline 20. I think the subject of physics and chemistry should be mandatory for all courses. & & & .692 & \\
\hline 21. I like studying physics and chemistry. & & & .651 & \\
\hline 22. Going to physics and chemistry classes is pleasant. & & & .620 & \\
\hline 23. I think physics and chemistry is useful in daily life. & & & & .753 \\
\hline 24. Physics and chemistry is important for my life. & & & & .735 \\
\hline 25. I feel like solving physics and chemistry activities is useful for my life. & & & & .705 \\
\hline 26. Studying physics and chemistry gives me competence. & & & & .614 \\
\hline \%variance explained & 21,8 & 18,7 & 17,1 & 11,3 \\
\hline
\end{tabular}

Note. "Items formulated in negative form in original questionnaire that were converted into positive statements in the scale applied in this study 
Table 2. Descriptive statistical analysis of the dimensions of the attitude towards physics and chemistry scale: Pre-test

\begin{tabular}{llll}
\hline Dimension & $\mathbf{N}$ & $\mathbf{M}$ & SD \\
\hline 1. Easiness & 558 & 4.52 & 1.24 \\
\hline 2. Negative affectivity & 558 & 5.46 & 1.18 \\
\hline 3. Motivation & 558 & 4.33 & 1.32 \\
\hline 4. Utility and competence & 558 & 4.79 & 1.26 \\
\hline The values above refer to the measurement scale of 1 to 7 & & &
\end{tabular}

The values above refer to the measurement scale of 1 to 7

Table 3. Dimensions of attitudes to physics and chemistry scale among students in the EG

\begin{tabular}{|c|c|c|c|c|}
\hline Dimension & & $\mathbf{N}$ & $\mathbf{M}$ & SD \\
\hline \multirow{2}{*}{ 1. Easiness } & Pre-test & 442 & 4.58 & 1.18 \\
\hline & Post-test & 442 & 4.60 & 1.24 \\
\hline \multirow{2}{*}{ 2. Negative affectivity } & Pre-test & 442 & 5.45 & 1.19 \\
\hline & Post-test & 442 & 5.31 & 1.28 \\
\hline \multirow{2}{*}{ 3. Motivation } & Pre-test & 442 & 4.35 & 1.26 \\
\hline & Post-test & 442 & 4.28 & 1.25 \\
\hline \multirow{2}{*}{ 4. Utility and competence } & Pre-test & 442 & 4.91 & 1.22 \\
\hline & Post-test & 442 & 4.95 & 1.17 \\
\hline
\end{tabular}

Table 4. Comparison between the dimensions of the attitude towards physics \& chemistry scale, as pre- \& post-test in the EG

\begin{tabular}{|c|c|c|c|c|c|c|}
\hline \multirow{2}{*}{ (Post-test/Pre-test) } & \multirow{2}{*}{ Difference of mean } & \multirow{2}{*}{ SD } & \multicolumn{2}{|c|}{$95 \%$ CI } & \multirow{2}{*}{$\mathbf{t}$} & \multirow{2}{*}{$\mathbf{p}$} \\
\hline & & & LB & UB & & \\
\hline 1. Easiness & .023 & .924 & -.076 & .122 & .458 & .647 \\
\hline 2. Negative affectivity & -.146 & 1.115 & -.266 & -.027 & -2.410 & .066 \\
\hline 3. Motivation & -.067 & 1.007 & -.175 & .041 & -1.227 & .221 \\
\hline 4. Utility and competence & .033 & 1.085 & -.083 & .150 & .565 & .573 \\
\hline
\end{tabular}

Note. CI-95\% confidence interval (Field, 2009); LB: Lower bound; UB: Upper bound

Table 5. Presentation of the mean values for the dimensions of the attitude towards physics \& chemistry scale, as pre-test \& post-test in the CG

\begin{tabular}{|c|c|c|c|c|}
\hline Dimension & & $\mathbf{N}$ & $\mathbf{M}$ & SD \\
\hline \multirow{2}{*}{ 1. Easiness } & Pre-test & 132 & 4.35 & 1.46 \\
\hline & Post-test & 132 & 4.16 & 1.38 \\
\hline \multirow{2}{*}{ 2. Negative affectivity } & Pre-test & 132 & 5.46 & 1.16 \\
\hline & Post-test & 132 & 4.94 & 1.20 \\
\hline \multirow{2}{*}{ 3. Motivation } & Pre-test & 132 & 4.21 & 1.41 \\
\hline & Post-test & 132 & 3.90 & 1.34 \\
\hline \multirow{2}{*}{ 4. Utility and competence } & Pre-test & 132 & 4.64 & 1.26 \\
\hline & Post-test & 132 & 4.32 & 1.26 \\
\hline
\end{tabular}

\section{Comparison of results between the $E G$ and the $C G$}

Given the existence of small differences in the means of all dimensions of the scale, for each group, we can consider that, at the start of the PVC project implementation, the attitudes of both groups (EG and CG) towards the physics and chemistry subject were equivalent. Thus, to help compare the EG attitudinal change from pre- to post-test, Table 3 presents the mean values of students' responses to ATPCS, and respective standard deviations.

The EG results in the pre-test and post-test were subjected to a paired samples t-test, as shown in Table 4, which revealed that the value of dimension 1(easiness) in the pre-test ( $M=4.58$, $\mathrm{SD}=1.18$ ) is slightly lower than the mean value in the post-test $(\mathrm{M}=4.60 \mathrm{SD}=1.24)$, as is also observed in dimension 4 (utility and competence) (pre-test: $\mathrm{M}=4.91, \mathrm{SD}=1.22$; post-test: $\mathrm{M}=4.95, \mathrm{SD}=1.17)$.

On the other hand, the values of dimensions 2 (negative affectivity) and dimension 3 (motivation) are higher in the pretest than in the post-test (dimension 2-pre-test: $\mathrm{M}=5.45$, $\mathrm{SD}=1.19$; post-test: $\mathrm{M}=5.31, \mathrm{SD}=1.28$; dimension 3 -pre-test:
$\mathrm{M}=4.35, \mathrm{SD}=1.26$; post-test: $\mathrm{M}=4.28, \mathrm{SD}=1.25$ ). Thus, as shown in Table 4, none of the ATPCS dimensions under analysis vary significantly from pre-test to post-test, in the EG.

The same procedures were performed to compare the attitudes of students in the CG, from pre- to post-test. As such, Table 5 shows the descriptive analysis of students' responses to ATPCS, in both moments of application.

Similarly, a paired samples t-test (Table 6) allowed us to conclude that, for all dimensions, the CG students exhibited less positive attitudes in the post-test compared to the pre-test (dimension 1-easiness-pre-test: $\mathrm{M}=4.35, \mathrm{SD}=1.46$; post-test: $\mathrm{M}=4.16, \mathrm{SD}=1.38$; dimension 2-negative affectivity-pre-test: $\mathrm{M}=5.46, \mathrm{SD}=1.16$; post-test: $\mathrm{M}=4.94, \mathrm{SD}=1.20$; dimension 3motivation-pre-test: $\mathrm{M}=4.21, \mathrm{SD}=1.41$; post-test: $\mathrm{M}=3.90$ $\mathrm{SD}=1.34$; dimension 4-utility and competence-pre-test: $\mathrm{M}=4.64, \mathrm{SD}=1.26$; post-test: $\mathrm{M}=4.32, \mathrm{SD}=1.26$ ). The results of the paired samples t-test (Table 6) indicate that, in the CG, the means of all dimensions significantly decreased from pre-test to post-test. 
Table 6. Comparison between the dimensions of the attitude towards physics \& chemistry scale, as pre- \& post-test in the CG

\begin{tabular}{|c|c|c|c|c|c|c|}
\hline \multirow{2}{*}{ (Post-test/Pre-test) } & \multirow{2}{*}{ Difference of mean } & \multirow{2}{*}{ SD } & \multicolumn{2}{|c|}{ 95\% CI } & \multirow{2}{*}{$\mathbf{t}$} & \multirow[b]{2}{*}{$\mathbf{p}$} \\
\hline & & & LB & UB & & \\
\hline 1. Easiness & -.198 & .929 & -.374 & -.022 & -2.224 & .028 \\
\hline 2. Negative affectivity & -.514 & 1.209 & -.743 & -.286 & -4.461 & $<.001$ \\
\hline 3. Motivation & -.318 & 1.010 & -.510 & -.126 & -3.284 & $<.001$ \\
\hline 4. Utility and competence & -.317 & 1.042 & -.515 & -.119 & -3.178 & .002 \\
\hline
\end{tabular}

Note. CI-95\% confidence interval (Field, 2009); LB: Lower bound; UB: Upper bound

Table 7. Comparison of the variations in the dimensions of the attitude towards physics \& chemistry scale, from pre- to posttest between the CG \& EG

\begin{tabular}{|c|c|c|c|c|c|c|}
\hline Dimension & & $\mathbf{N}$ & Difference of mean & SD & $\mathbf{F}$ & $\mathbf{p}$ \\
\hline \multirow{2}{*}{ 1. Easiness } & CG & 132 & -.198 & .93 & \multirow{2}{*}{4.700} & \multirow{2}{*}{.031} \\
\hline & EG & 442 & .023 & .92 & & \\
\hline \multirow{2}{*}{ 2. Negative affectivity } & $\mathrm{CG}$ & 132 & -.514 & 1.21 & \multirow{2}{*}{8.653} & \multirow{2}{*}{.003} \\
\hline & EG & 442 & -.146 & 1.12 & & \\
\hline \multirow{2}{*}{ 3. Motivation } & CG & 132 & -.318 & 1.01 & \multirow{2}{*}{5.093} & \multirow{2}{*}{.025} \\
\hline & EG & 442 & -.067 & 1.01 & & \\
\hline \multirow{2}{*}{ 4. Utility and competence } & CG & 132 & -.317 & 1.04 & \multirow{2}{*}{8.768} & \multirow{2}{*}{.003} \\
\hline & EG & 442 & .033 & 1.09 & & \\
\hline
\end{tabular}

To better understand the differences between groups, observed from pre-test to post-test, an ANOVA analysis was conducted with the results of the ATPCS. Thus, Table 7 summarizes Table 4 and Table 6 , as well as presents the results of the ANOVA analysis conducted. According to these data, the variation of dimension 1 (easiness) is greater for the EG $(\Delta \mathrm{M}=.023, \mathrm{SD}=.92)$ compared to the CG $(\Delta \mathrm{M}=-.198$, $\mathrm{SD}=.93$ ), as also occurs for dimension 4 (utility and competence) (EG: $\Delta \mathrm{M}=.033, \mathrm{SD}=1.09$; $\mathrm{CG}: \Delta \mathrm{M}=-.317, \mathrm{SD}=1.04$ ), with both situations revealing a slight increase in the EG and a decrease in the CG. The variation of the dimension 2 (negative affectivity) is also higher for the $\mathrm{EG}(\Delta \mathrm{M}=-.146, \mathrm{SD}=1.12)$ compared to the CG $(\Delta \mathrm{M}=-.514, \mathrm{SD}=1.21)$, with the EG exhibiting a lower decrease than the CG. Similarly, the variation of dimension 3 (motivation) is also superior for the $\mathrm{EG}(\Delta \mathrm{M}=-.067, \mathrm{SD}=1.01)$ when compared to the variation of the CG $(\Delta \mathrm{M}=-.318$, $\mathrm{SD}=1.01$ ), having decreased less in the EG than in the CG.

Thus, considering the results of the ANOVA analysis (Table 7), there is a significantly more positive change in the four dimensions of this scale for the EG compared to the CG.

In addition to the above results on students' attitudes, in the next section we will present the main results for the content analysis of the interviews with teachers which are directly related to the impact of the project on the teaching practices of the participating chemistry teachers.

\section{Notes from Interviews with Teachers}

In order to gather additional and complementary information regarding the impact of the PVC project, we invited the nine teachers to be voluntarily interviewed. The interviews were conducted in Portuguese; therefore, the quotes presented in this section were translated from Portuguese into English by the first author and validated by the other two authors and a native English speaker.

As teachers referred, the PVC project proved to be an added value to their teaching practices, as it contributed to the diversification of the pedagogical dynamics used in their classes ("To me, it was very positive in the way that I was able to apply a different and motivating project for the students in my classes" [teacher 1]), provided materials and resources that allowed them to continue implementing the project activities with other students later on ("With the materials provided, we were able to do the analyses and the tests with other students" [teacher 2]). It also promoted teachers' continuous learning to keep themselves updated not only in relation to the context, but also, and especially, regarding the chemistry contents explored in the project that were not directly integrated in the Chemistry curricula ("Even for my learning since it also forced me to research some things to be able to guide the students through the project" [teacher 3]; "The PVC project contributed to learning new and simple laboratory techniques" [teacher 4]). Another relevant aspect mentioned by teachers as an added value of the PVC project was the enhanced interdisciplinarity.

\section{DISCUSSION}

According to Vilia and Candeias (2020), the cognitive dimension of learning tends to have a central role in teaching practices, with the affective dimension assuming a subsidiary role. In the case of chemistry, it is often portrayed in the literature as one of the subjects towards which students tend to have more negative attitudes (Ibrahim \& Iksan, 2018; Osborne et al., 2003; Salta \& Tzougraki, 2004). This negativity towards chemistry may be largely influenced by the teacher and the pedagogical practices used to teach the contents of this subject (Cheung, 2009). Since citizen science is proving to be a pedagogical approach with the potential to promote the affectivity of students towards school and scientific subjects (Ruiz-Mallén et al., 2016), with this research, we sought to understand the impact of students' participation in a PVC citizen science project, particularly on their attitudes towards the physics and chemistry subject. For this purpose, we applied the ATPCS as a pre-test and as a post-test.

According to Eagly and Chaiken (1993), the overall psychological construct of attitude is often divided into cognitive, affective, and behavioural components. AalderenSmeets et al. (2012) adapted the traditional tripartite model of 
attitude proposed by Eagly and Chaiken (1993) and proposed a fourth attitudinal main component: cognitive beliefs, affective states and perceived control, which led to behavioural intentions. And the four dimensions that emerged from the ATPCS analysis could be interpreted as subcategories of those components. The dimension 4 (utility and competence) could be interpreted as a subcategory of cognitive beliefs component; the dimension 2 (negative affectivity) and dimension 3 (motivation) are subcategories of affective states component; and the perceived control component encompasses the dimension 1 (easiness). The behavioural component was not assessed in the ATPCS.

The analysis of the dimensions resulting from the PCA conducted for this scale indicated that, in the pre-test, the CG and EG students already had positive attitudes towards the four attitude dimensions of the ATPCS. For both groups, dimension 2 (negative affectivity) stood out as the one in which students showed more positive attitudes. On the other hand, dimension 3 (motivation) was the one in which students' responses exhibited a lower mean value. In this regard, Pires et al. (2017) also found the motivation dimension of the chemistry subject to be the one in which students tend to show less positive results. The application of the ATPCS as a posttest revealed that the attitudes of CG students towards the four ATPCS dimensions decreased significantly, from pre-test to post-test. Coll et al. (2006), as well as Ibrahim and Iksan (2018), report that, in general, students consider chemistry a difficult science to learn, which may be a factor that explains why these students' attitudes decreased over the course of the school year, as many of the participating students were attending the class for the first time. Regarding the EG, it was found that, from pre- to post-test, although attitudes were more positive in the easiness and utility and competence dimensions, these changes in attitudes did not reveal significant differences between these two moments of data collection. Still regarding the group effect on changes in students' attitudes, there was a positive change in the mean of the attitudes among the EG, from pre-test to post-test, in the easiness and utility and competence dimensions, as well as a negative change in the negative affectivity and motivation dimensions. However, the attitude changes were significantly higher in the EG, compared to the differences observed in the CG. Thus, according to these results, at the beginning of the school year (application of the ATPCS as a pre-test), the CG and EG students exhibited positive attitudes towards the physics and chemistry subject, contrary to the literature indicating that students have negative or neutral attitudes towards this subject (Ibrahim \& Iksan, 2018; Osborne \& Collins, 2000; Salta \& Tzougraki, 2004). However, Dalgety et al. (2003) and Salta and Tzougraki (2004) report that students' attitudes towards chemistry tend to decrease as they progress in their academic career. According to Salta and Tzougraki (2004), this fact may be influenced by "the content of chemistry curriculum, the chemistry lessons time, the methods of teaching chemistry (...), and the lack of laboratory experiments" (p. 544). Similarly, this occurred for the CG, whose attitudes became significantly less positive (or even negative), from the beginning to the end of the school year, as mentioned above. On the other hand, given the pedagogical potential (Straub, 2020), especially in the affective domain, of citizen science approaches (Ballard et al., 2017; Harlin et al., 2018), due to students' involvement in the scientific process and the promotion of context-based learning (Bellocchi et al., 2016; Dawson \& Carson, 2017), we expected the attitudes of EG students towards the subject to be significantly enhanced. However, we found that the attitudes of students in this group did not experience such a significant decrease, from pre-test to post-test, as did the attitudes of CG students for all the four dimensions. Although there was no significant positive change from pre-test to post-test in the EG, the results obtained in this study show the PVC project promoted more positive attitudes in the EG students, which counteracted the negative trend observed over the school year for the CG students, previously reported by Dalgety et al. (2003), as well as Salta and Tzougraki (2004). As mentioned in the literature, the pedagogical practices implemented or the themes explored in the classroom (Cardellini, 2012; Cheung, 2011; Sharpe \& Abrahams, 2020) are essential for the success of chemistry teaching and have great influence on students' attitudes towards the subject. In the particular case of citizen science pedagogical approaches, Harlin et al. (2018) state their potential is highly dependent on the teacher's role. Thus, it was also important to understand the impact of the project on the teaching practices of the teachers participating in the PVC project. They considered the PVC project to be an asset, because it helped to diversify the pedagogical dynamics they used, provided materials and resources that allowed them to continue developing the project activities with other students. The project also promoted continuous learning among teachers, allowing them to remain updated on the context explored, as well as on the chemistry contents addressed in the project and which were not part of the Portuguese KS3 physics and chemistry curricula. Moreover, the teachers also recognize the important contribution of the PVC project to learning new laboratory techniques, making them better and more capable professionals.

Another aspect that teachers mentioned in their interviews as an asset of the PVC project was the interdisciplinarity it fostered. This interdisciplinary, promoted between the subject of chemistry and several other areas, such as natural sciences, Portuguese, English, ICT, arts, mathematics, and citizenship, was a significant contribution, because it allowed teachers to respond to the flexibility of the project and contributed to teachers' professional training in new pedagogical approaches. Additionally, in teachers' perspective, PVC project promote students' chemistry learning and the development of different skills, such as work autonomy, particularly in the laboratory, argumentation, reflection, group work, communication and discussion of ideas among peers and the general public, which are considered essential skills for the education of students in the $21^{\text {st }}$ century (Stehle \& Peters-Burton, 2019; Taber, 2016).

Attesting to the relevance of the PVC project in terms of teaching practices, the Curriculum Management: Experimental Sciences Education Report, of the General Inspectorate of Education and Sciences, which provides an evaluation of one of the schools involved in the project, mentions the project participation as one of the most positive initiatives that aimed to stimulate students' pleasure for science and research (IGEC, 2021). 


\section{CONCLUSIONS}

This study allowed us to observe that the attitudes of EG and CG students towards physics and chemistry were positive and equivalent at the beginning of the school year. However, there was a negative change in the attitudes of the CG students, in the post-test, for all dimensions (easiness, negative affectivity, motivation, and utility and competence). On the other hand, for the EG students, no dimension revealed significant attitude changes between the two moments of data collection. Nonetheless, this group exhibited positive attitude changes in the easiness and utility and competence dimensions, and the negative changes in the negative affectivity and motivation dimensions were considerably higher in the EG compared to the CG. The analysis of results also indicates the changes in attitudes towards the physics and chemistry subject differ significantly according to group, which suggests a positive impact of the PVC project on the EG. This positive impact is not due to significantly positive changes in the attitudes of EG students from pre-test to posttest, but rather because it counteracts the trend of negative changes in attitude that occurred over the school year for students in the CG. The pedagogical approaches implemented and the contexts explored in the classroom can have a strong influence on students' attitudes towards the subject. Thus, it was also important for us to understand the contributions of the PVC project for the teaching practices of participating teachers. The results suggest that implementing a citizen science approach was very positive for teachers. They recognized the project as an asset for their professional training, which helped them to diversify pedagogical dynamics and acquire knowledge about the chemistry underlying the contexts of water quality and marine litter. Furthermore, teachers also highlighted that providing materials and resources enabled them to continue the implementation of PVC project activities, after the conclusion of this study. In addition, teachers recognized the potential for interdisciplinarity provided by this educational experience. In the opinion of teachers, the PVC project dynamics were also important in helping students to develop new skills.

In summary, the activities developed in the PVC project contributed to the professional training of teachers, by offering new pedagogical approaches that enhance the quality of chemistry teaching and learning, as well as the development of various skills in students. Thus, considering our results, we can conclude that citizen science approaches, in the field of chemistry, reveal great potential in terms of promoting the affective dimension of chemical literacy, as well as providing positive contributions to the professional development and quality of teachers' lessons. Given the results observed in the CG, there is an urgent need to reflect on the pedagogical practices commonly used in the teaching of physics and chemistry.

The overall positive results of the PVC project are good indicators of the pedagogical potential of citizen science, opening doors for future research involving other contexts, chemistry contents, and/or students from different grades.
Author contributions: All co-authors have involved in all stages of this study while preparing the final version. They all agree with the results and conclusions.

Funding: This work was supported by the Fundação para a Ciencia e Tecnologia [Foundation for Science and Technology] (FCT, Lisbon) under Grant SFRH/BD/132482/2017 and under CIQUP, Faculty of Science, University of Porto (UIDB/00081/2020) and IMS- Institute of Molecular Sciences (LA/P/0056/2020) funding.

Acknowledgements: The authors would like to thank to the teachers and the students who took part in UIDB/00081/2020 project and greatly contributed to its success.

Declaration of interest: The authors declare that they have no competing interests.

Ethics approval and consent to participate: Not applicable.

Availability of data and materials: All data generated or analyzed during this study are available for sharing when appropriate request is directed to corresponding author.

\section{REFERENCES}

Aalderen-Smeets, S. I., Molen, J. H. W., \& Asma, L. J. (2012). Primary teachers' attitudes toward science: A new theoretical framework. Science Education, 96(1), 158-182. https://doi.org/10.1002/sce.20467

Aikenhead, G. S. (2003). Chemistry and physics instruction: Integration, ideologies, and choices. Chemistry Education Research and Practice, 4(2), 115-130. https://doi.org/10. 1039/B2RP90041F

Altundag, C. K., \& Alkan, F. (2018). The effect of context-based learning on the attitude towards the daily life chemistry. Uluslararası Bilimsel Araştırmalar Dergisi [International Journal of Scientific Research], 38-44. https://doi.org/ 10.21733/ibad.423559

Araújo, J. L., Morais, C., \& Paiva, J. C. (2020). Developing and implementing a low-cost, portable pedagogical kit to foster students' water quality awareness and engagement by sampling coastal waters and analyzing physicochemical properties. Journal of Chemical Education, 97(10), 36973701. https://doi.org/10.1021/acs.jchemed.0c00333

Araújo, J. L., Morais, C., \& Paiva, J. C. (2021). Student participation in a coastal water quality citizen science project and its contribution to the conceptual and procedural learning of chemistry. Chemistry Education Research and Practice, 23, 100-112. https://doi.org/10.1039/ D1RP00190F

Ballard, H. L., Dixon, C. G. H., \& Harris, E. M. (2017). Youthfocused citizen science: Examining the role of environmental science learning and agency for conservation. Biological Conservation, 208, 65-75. https://doi.org/10.1016/j.biocon.2016.05.024

Bellocchi, A., King, D. T., \& Ritchie, S. M. (2016). Contextbased assessment: Creating opportunities for resonance between classroom fields and societal fields. International Journal of Science Education, 38(8), 1304-1342. https://doi.org/10.1080/09500693.2016.1189107 
Bonn, A., Hecker, S., Bowser, A., Makuch, Z., Vogel, J., \& Haklay, M. (2018). Citizen science to foster innovation in open science, society and policy. In S. Hecker, M. Haklay, A. Bowser, Z. Makuch, J. Vogel, \& A. Bonn (Eds.), Citizen science: Innovation in open science, society and policy (pp. 465-484). UCL Press. https://doi.org/10.2307/j.ctv550cf2.38

Briggs, S. R., \& Cheek, J. M. (1986). The role of factor analysis in the development and evaluation of personality scales. Journal of Personality, 54(1), 106-148. https://doi.org/10. 1111/j.1467-6494.1986.tb00391.x

Cardellini, L. (2012). Chemistry: Why the subject is difficult? Educación Química [Chemical Education], 23, 305-310. https://doi.org/10.1016/S0187-893X(17)30158-1

Cavas, P. H., Ozdem, Y., Cavas, B., Cakiroglu, J., \& Ertepinar, H. (2013). Turkish pre-service elementary science teachers' scientific literacy level and attitudes toward sience. Science Education International, 24(4), 383-401.

Chang, R., \& Goldsby, K. (2014). Chemistry. McGraw-Hill Education.

Chang, S. N., \& Chiu, M. H. (2005). The development of authentic assessments to investigate ninth graders' scientific literacy: In the case of scientific cognition concerning the concepts of chemistry and physics. International Journal of Science and Mathematics Education, 3, 117-140. https://doi.org/10.1007/s10763-004-5239-0

Cheung, D. (2009). Students' attitudes toward chemistry lessons: The interaction effect between grade level and gender. Research in Science Education, 39(1), 75-91. https://doi.org/10.1007/s11165-007-9075-4

Cheung, D. (2011). Evaluating student attitudes toward chemistry lessons to enhance teaching in the secondary school. Educación Química [Chemical Education], 22(2), 117122. https://doi.org/10.1016/S0187-893X(18)30123-X

Coll, R. K., Ali, S., Bonato, J., \& Rohindra, D. (2006). Investigating first-year chemistry learning difficulties in the South Pacific: A case study from Fiji. International Journal of Science and Mathematics Education, 4, 365-390. https://doi.org/10.1007/s10763-005-9007-6

Costello, A., \& Osborne, J. (2005). Best practices in exploratory factor analysis: Four recommendations for getting the most from your analysis. Practical Assessment, Research \& Evaluation, 10(7), 1-9. https://doi.org/10.7275/jyj1-4868

Dalgety, J., Coll, R. K., \& Jones, A. (2003). Development of chemistry attitudes and experiences questionnaire (CAEQ). Journal of Research in Science Teaching, 40(7), 649668. https://doi.org/10.1002/tea.10103

Dawson, V., \& Carson, K. (2017). Using climate change scenarios to assess high school students' argumentation skills. Research in Science \& Technological Education, 35(1), 1-16. https://doi.org/10.1080/02635143.2016.1174932

Eagly, A., \& Chaiken, S. (1993). The psychology of attitudes. Wadsworth group/Thomson Learning.

European Citizen Science Association. (2020). ECSA's characteristics of citizen science. ECSA, 1-6.

European Commission. (2014). Special eurobarometer 416 "Attitudes of European citizens towards the environment". Directorate-General for Communication.
Fernandes, C. A. F. (2007). A matemática na disciplina de ciências físico-quimicas: um estudo sobre as atitudes de alunos do $9^{\circ}$ ano de escolaridade [Mathematics in the discipline of physical and chemical sciences: A study on the attitudes of students in the 9th-year of schooling] [Master's thesis, Universidade do Minho].

Field, A. (2009). Discovering statistics using SPSS. SAGE.

Follett, R., \& Strezov, V. (2015). An analysis of citizen science based research: Usage and publication patterns. PLOS ONE, 10(11), e0143687, 1-14. https://doi.org/10.1371/journal. pone. 0143687

Gilbert, J. K., \& Treagust, D. F. (Eds.). (2009). Multiple representations in chemical education. Springer. https://doi.org/10.1007/978-1-4020-8872-8

Hansson, L., Hansson, Ö., Juter, K., \& Redfors, A. (2021). Curriculum emphases, mathematics and teaching practices: Swedish upper-secondary physics teachers' views. International Journal of Science and Mathmatics Education 19, 499-515. https://doi.org/10.1007/s10763020-10078-6

Harlin, J., Kloetzer, L., Patton, D., Leonhard, C., \& Students. (2018). Turning students into citizen scientists. In S. Hecker, M. Haklay, A. Bowser, Z. Makuch, J. Vogel, \& A. Bonn (Eds.), Citizen science: Innovation in open science, society and policy (pp. 410-428). UCL Press. https://doi.org/10.2307/j.ctv550cf2.35

Hecker, S., Garbe, L., \& Bonn, A. (2018). The European citizen science landscape-a snapshot. In S. Hecker, M. Haklay, A. Bowser, Z. Makuch, J. Vogel, \& A. Bonn (Eds.), Citizen science: Innovation in open science, society and policy (pp. 190-200). UCL Press. https://doi.org/10.2307/j.ctv550cf2. 20

Heng, C. K., \& Karpudewan, M. (2015). The interaction effects of gender and grade level on secondary school students' attitude towards learning chemistry. Eurasia Journal of Mathematics, Science \& Technology Education, 11(4), 889898. https://doi.org/10.12973/eurasia.2015.1446a

Hofstein, A., \& Mamlok-Naaman, R. (2011). High-school students' attitudes toward and interest in learning chemistry. Educación Química [Chemical Education], 22(2), 90-102. https://doi.org/10.1016/S0187-893X(18)30121-6

Hofstein, A., Ben-Zvi, R., Damuel, D., \& Tamir P. (1977). Attitudes of Israeli high school students toward chemistry and physics: A comparitive study. Science Education, 61, 259-268. https://doi.org/10.1002/sce.3730610217

Ibrahim, N. H. B., \& Iksan, Z. B. (2018). Level of chemophobia and relationship with attitude towards chemistry among science students. Journal of Educational Sciences, 2(2), 5265. https://doi.org/10.31258/jes.2.2.p.52-65

IGEC, Inspeção-Geral da Educação e Ciência. (2019). Gestão do currículo: Ensino experimental das ciências. Relatório: Escola secundária de estarreja [Curriculum management: Experimental sciences education report, of the general inspectorate of education and sciences: Estarreja secondary school]. Inspeção-Geral da Educação e Ciência [General Inspection of Education and Science] (IGEC).

Kaiser. (1974). An index of factorial simplicity. Psychometrika, 39, 31-36. https://doi.org/10.1007/BF02291575 
Kelemen-Finan, J., Scheuch, M., \& Winter, S. (2018). Contributions from citizen science to science education: An examination of a biodiversity citizen science project with schools in Central Europe. International Journal of Science Education, 40(17), 2078-2098. https://doi.org/ 10.1080/09500693.2018.1520405

Kohen, Z., Herscovitz, O., \& Dori, Y. J. (2020). How to promote chemical literacy? On-line question posing and communicating with scientists. Chemistry Education Research and Practice, 21(1), 250-266. https://doi.org/ 10.1039/C9RP00134D

Lu, Y.-Y., Chen, H.-T., Hong, Z.-R., \& Yore, L. D. (2016). Students' awareness of science teachers' leadership, attitudes toward science, and positive thinking, International Journal of Science Education, 38(13), 21742196. https://doi.org/10.1080/09500693.2016.1230792

Motion, A. (2019). What can citizen science do for us? Chemistry world. https://www.chemistryworld.com/opinion/whatcan-citizen-science-do-for-us/3010269.article

Neto, A., Candeias, A. A., Rebelo, N., Varelas, D., \& Diniz, A. M. (2013). Validade estrutural do questionário de atitudes face às ciências físico-químicas: Estudo com alunos do $9^{\circ}$ ano ensino básico português [Structural validity of the attitudes towards physical and chemical sciences questionnaire: A study with 9th grade Portuguese primary school students]. In XII Congresso Internacional GalegoPortuguês de Psicopedagogia [XII Galician-Portuguese International Congress of Psychopedagogy]. Universidade Minho, Braga, Portugal.

Neto, A., Candeias, A., Pomar, C., Costa, P., Oliveira, M., Silva, S., Silva, J., \& Rebelo, N. (2011). Questionários de atitudes face às ciências físico-químicas (QAFCFQ) em alunos portugueses do ensino básico: Estudo psicométrico [Attitudes towards physical and chemical sciences questionnaire (ATPCSQ) in Portuguese primary school students: Psychometric study]. In XI Congreso Internacional Galego-Portugués de Psicopedagoxía [XI International Galician-Portuguese Congress of Psychopedagogy]. Universidade da Corunha, Corunha, Espanha.

Osborne, J., \& Collins, S. (2000). Pupils' and parents' views of the school science curriculum: A study funded by the Wellcome Trust. King's College, London.

Osborne, J., Simon, S., \& Collins, S. (2003). Attitudes towards science: A review of the literature and its implications. International Journal of Science Education, 25(9), 1049-1079. https://doi.org/10.1080/0950069032000032199

Pires, H. S., Candeias, A. A., Grácio, L., Galindo, E., \& Melo, M. (2017). The influence of family support according to gender in the Portuguese language course achievement. Frontiers in Psychology, 8(1064), 90-97. https://doi.org/10.3389/ fpsyg.2017.01610

Ruiz-Mallén, I., Riboli-Sasco, L., Ribrault, C., Heras, M., Laguna, D., \& Perié, L. (2016). Citizen science: Toward transformative learning. Science Communication, 38(4), 523-534. https://doi.org/10.1177/1075547016642241
Salta, K. \& Tzougraki, C. (2004). Attitudes toward chemistry among 11th grade students in high schools in Greece. Science Education, 88(4), 535-547. https://doi.org/10.1002/ sce.10134

Scheuch, M., Panhuber, T., Winter, S., Kelemen-Finan, J., Bardy-Durchhalter, M., \& Kapelari, S. (2018). Butterflies \& wild bees: Biology teachers' PCK development through citizen science. Journal of Biological Education, 52(1), 79-88. https://doi.org/10.1080/00219266.2017.1405530

Sharpe, R., \& Abrahams, I. (2020). Secondary school students' attitudes to practical work in biology, chemistry and physics in England. Research in Science \& Technological Education, 38(1), 84-104. https://doi.org/10.1080/ 02635143.2019 .1597696

Shwartz, Y., Ben-Zvi, R., \& Hofstein, A. (2006). The use of scientific literacy taxonomy for assessing the development of chemical literacy among high-school students. Chemistry Education Research and Practice, 7(4), 203-225. https://doi.org/10.1039/B6RP90011A

Stehle, S. M., \& Peters-Burton, E. E. (2019). Developing student $21^{\text {st }}$ century skills in selected exemplary inclusive STEM high schools. International Journal of STEM Education, 6(39), 1-15. https://doi.org/10.1186/s40594019-0192-1

Strasser, B., Baudry, J., Mahr, D., Sanchez, G., \& Tancoigne, E. (2019). "Citizen science"? Rethinking science and public participation. Science \& Technology Studies, 32(2), 52-76. https://doi.org/10.23987/sts.60425

Straub, M. C. P. (2020). A study of student responses to participation in online citizen science projects. International Journal of Science and Mathematics Education, 18, 869-886. https://doi.org/10.1007/s10763-019-10001-8

Taber, K. S. (2016). Learning generic skills through chemistry education. Chemistry Education Research and Practice, 17, 225-228. https://doi.org/10.1039/c6rp90003h

Talanquer, V., \& Sevian, H. (2014). Chemistry in past and new science frameworks and standards: Gains, losses, and missed opportunities. Journal of Chemical Education, 91(1), 24-29. https://doi.org/10.1021/ed400134c

Tulloch, A. I. T., Possingham, H. P., Joseph, L. N., Szabo, J., \& Martin, T. G. (2013). Realising the full potential of citizen science monitoring programs. Biological Conservation, 165, 128-138. https://doi.org/10.1016/j.biocon.2013.05.025

Tytler, R., \& Osborne, J. (2012). Student attitudes and aspirations towards science. In B. J. Fraser, K. G. Tobin, \& C. J. McRobbie (Eds.), Second international handbook of science education. Springer. https://doi.org/10.1007/978-14020-9041-7_41

Vilia, P. N., Candeias, A. A., Neto, A. S., Franco, M. S., \& Melo, M. (2017). Academic achievement in physics-chemistry: The predictive effect of attitudes and reasoning abilities. Frontiers in Psychology, 8, 81-89. https://doi.org/10.3389/ fpsyg.2017.01064 
Vilia, P., \& Candeias, A. A. (2020). Attitude towards the discipline of physics-chemistry and school achievement: revisiting factor structure to assess gender differences in Portuguese high-school students. International Journal of Science Education, 42(1), 133-150. https://doi.org/10.1080/ 09500693.2019.1706012 